Viso - Cadernos de estética aplicada Revista eletrônica de estética

ISSN 1981-4062

$\mathrm{N}^{\circ} 2$, mai-ago/2007

http://www.revistaviso.com.br/

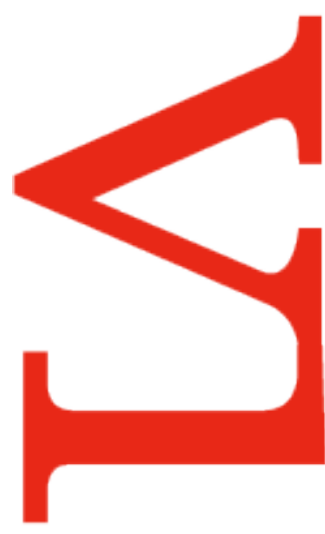

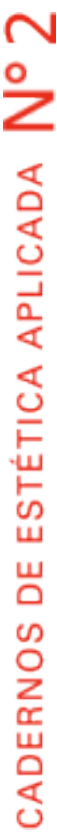
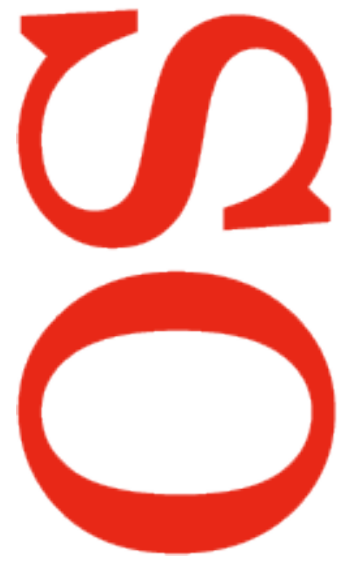

\title{
Teoria e estética em Aristóteles Francisco Moraes
}




\section{RESUMO}

\section{Teoria e estética em Aristóteles}

Procuramos mostrar, neste artigo, como a experiência estética representa, para Aristóteles, a própria origem e começo da filosofia, e não simplesmente um ramo específico da reflexão filosófica. A filosofia é desencadeada justamente pelo maravilhamento diante daquilo que não se conhece. A admiração (thaumázein) nos torna devedores de um encontro inaugural com algo que se apresenta por si mesmo, de maneira incontrolável. Nisso, precisamente, consiste a experiência estética, a experiência da beleza, para a qual converge toda teorização.

Palavras-chave: estética - teoria - Aristóteles

\section{ABSTRACT}

\section{Theory and aesthetics in Aristotle}

This article tries to show how aesthetic experience works for Aristotle as the origin and beginning of philosophy itself, and not merely as one specific branch of philosophical reflection. Philosophy is put into action by the fascination before something that is not known. The admiration (thaumázein) forces us to face an original encounter with something that stands for itself in an uncontrollable manner. It is precisely that which makes up aesthetic experience, the experience of beauty, towards which all theorizing converges.

Keywords: aesthetics - theory - Aristotle 
MORAES, F. "Teoria e estética em Aristóteles". In: Viso:

Cadernos de estética aplicada, v. I, n. 2 (mai-ago/2007), pp. 14-27.

DOI: $10.22409 / 1981-4062 / v 2 i / 37$

Aprovado: 30.06.2007. Publicado: 12.08.2007.

(C) 2007 Francisco Moraes. Esse documento é distribuído nos termos da licença Creative Commons Atribuição-NãoComercial 4.0 Internacional (CC-BY-NC), que permite, exceto para fins comerciais, copiar e redistribuir o material em qualquer formato ou meio, bem como remixá-lo, transformá-lo ou criar a partir dele, desde que seja dado o devido crédito e indicada a licença sob a qual ele foi originalmente publicado.

Licença: http://creativecommons.org/licenses/by-nc/4.0/deed.pt BR

Accepted: 30.06.2007. Published: 12.08.2007.

(C) 2007 Francisco Moraes. This document is distributed under the terms of a Creative Commons Attribution-NonCommercial 4.0 International license (CC-BY-NC) which allows, except for commercial purposes, to copy and redistribute the material in any medium or format and to remix, transform, and build upon the material, provided the original work is properly cited and states its license.

License: http://creativecommons.org/licenses/by-nc/4.0/ 
Talvez não seja nenhum exagero dizer que Aristóteles foi o filósofo que inaugurou a reflexão propriamente estética acerca da arte (mais particularmente acerca da poesia e de seus gêneros), assim como também devem ser tributadas a ele as primeiras reflexões eminentemente políticas acerca da ação. Isso não se deve ao fato de a poesia e a ação terem sido, antes dele, desprezadas pela filosofia, mas antes ao fato de a reflexão filosófica ou teórica ainda alimentar, antes dele, pretensões poéticas e políticas. Somente com Aristóteles a filosofia separa-se, ao mesmo tempo, da política e da poesia e entregase à tarefa de encontrar o seu próprio terreno. ${ }^{1}$ Não por acaso, ao mesmo tempo em que renuncia a compor mitos, Aristóteles também abandona ao prudente, explicitamente, a direção dos negócios da cidade. Nesse contexto, ao pronunciar-se sobre a poesia ou sobre a ação, somente indiretamente a reflexão teórica se envolverá com uma e outra. A teoria será agora "teoria aplicada" quando se ocupar de tais temas, e não mais teoria pura. Quem se dedica a pensar a ação e a poesia não precisa ser ele mesmo um homem de ação ou um poeta; basta encontrar o método ou o caminho adequado, a fim de não esperar de tais investigações aquilo que, por princípio, elas não podem proporcionar. $^{2}$

Já para nós, hoje, não é algo difícil admitir a importância das reflexões estéticas acerca da arte. Isso se deve talvez ao fato de a arte já não conseguir escapar às malhas cada vez mais finas da teorização explicativa e classificatória. De fato, no momento em que tudo parece depender tão somente da propaganda para ser o que é, a necessidade do crivo teórico faz-se até mesmo impositiva. Cada vez mais é preciso aprender a distinguir o que é arte verdadeira daquilo que não passa de embuste, melhor dizendo, de mera promoção mercadológica da indústria de entretenimento. Mas e se o próprio crivo teórico já tivesse sido incorporado à indústria como estratégia de valorização de seus produtos? E se nós mesmos, quando damos ouvidos a todo tipo de crítica e literatura estetizante, estivéssemos apenas querendo garantir os nossos direitos de consumidores de "arte genuína"? Neste caso, onde está a arte, onde a teoria?

Mais difícil, bem mais difícil de admitir do que a reflexão estética, é, para nós, o papel que desempenha no conhecimento o momento da sedução e do entusiasmo puramente estéticos. Nomeamos de entusiasmo estético o momento em que uma coisa (ou alguém) chama verdadeiramente a atenção para si. Ela está aí, sem dúvida, bem diante de nós, mas não está aí como algo que possamos simplesmente constatar. $O$ entusiasmo estético que uma coisa desperta em nós nos enche de fascínio e admiração, desencadeando assim a busca de conhecimento. É o encontro com algo surpreendente que, abalando os nossos pressupostos habituais, desperta em nós o interesse de conhecer, o que já é mais do que uma mera curiosidade. Aristóteles e Platão chamavam esse encontro surpreendente com o que desde si mesmo se revela surpreendente de espanto ou admiração [thaumázein], e identificavam-no como o começo da própria filosofia e de todo desejo de saber. 
Precisamente o caráter estético desse encontro com o que não se conhece parece-nos hoje algo por demais irracional para ser admitido no seio de um conhecimento rigoroso. Um renomado filósofo da ciência teve recentemente seu trabalho contestado precisamente por admitir a importância do fascínio estético na conversão de todo um grupo de cientistas a um novo paradigma teórico. ${ }^{3}$ Para Aristóteles, porém, não resta dúvida de que o choque com o desconhecido, o fascínio por algo que nos perturba com a sua presença inquietante e incontrolável, está na origem de todo conhecimento. É o que se pode ver na seguinte passagem:

Pois foi através da admiração que os homens tanto agora quanto outrora começaram a filosofar; de início, admirados pelas aporias mais surpreendentes, em seguida, aos poucos, partiram para problemas maiores, como acerca das mudanças da lua, acerca do sol e dos astros, bem como das gerações todas. Mas aquele que está em aporia e se admira crê ignorar (por isso o filósofo é também um "philômito": pois o mito é uma reunião de maravilhas); de modo que se foi para escaparem da ignorância que filosofaram, é claro que buscaram o saber pelo saber mesmo e não por causa de alguma utilidade. ${ }^{4}$

Esse desconhecido fascinante, de que fala Aristóteles, é mais do que um simples "quebra-cabeça" a desafiar o nosso orgulho intelectual e a estimular eletricamente nossos neurônios. Em causa está a atração pelo desconhecido, a fascinação por algo que não se conhece, mas que nem por isso deixa de trazer toda uma riqueza de pressentimentos. A admiração é aquilo que nos impele realmente ao empenho de conhecer, de modo que ficamos desejosos de saber. Nesse caso, não procuramos saber apenas para ficarmos inteirados, ou mesmo para solucionar uma dificuldade que nos deixa atormentados; o que se busca é antes o saber pelo saber mesmo, melhor dizendo, pelo sabor de saber.

Não por acaso Aristóteles afirma que o filósofo é um "filômito", um amigo do mito, pois o mito não é um discurso que se destine apenas a ser entendido; melhor dizendo, o mito não é um discurso que possa terminar de ser entendido. Quem pretende esgotar o significado de um mito, reduzindo-o a uma mensagem determinada, só mostra com isso estar fora do alcance de seu fascínio. Todo mito é inesgotável em seu dizer. O mito é, assim, um dizer que não termina nunca de dizer o que diz, da mesma forma que a filosofia é um ver que nunca cessa de ver o que viu. Na amizade pelo mito repercute a amizade pelo saber. Na origem de todo conhecimento está, portanto, o prazer estético da contemplação, algo que nos libera de nós mesmos e que nos faz ficar inteiramente entregues à presença de um outro. O momento inaugural do conhecimento é deste modo o reconhecimento de que um outro existe como outro, o que exige o maravilhamento diante do belo. Nesse sentido, só o que é belo ${ }^{5}$ merece ser conhecido. Sem a revelação desconcertante da beleza ficamos sempre na dúvida a respeito de se algo existe realmente além de nós mesmos.

O que aqui se está chamando de revelação desconcertante da beleza é algo tão simples e imediato que já não autoriza nenhum recuo para buscar causas e explicações; algo tão 
simples e imediato quanto o prazer das sensações. E como poderíamos ignorar que este último representa uma fonte inesgotável de experiências e de novos conhecimentos? De fato, não começamos nossa existência de seres descobridores através de exercícios lógicos puramente racionais, mas através das experiências simples que nos abrem nossos sentidos. Caso já não estivéssemos destinados ao conhecimento desde esse momento, como, mais tarde, poderíamos despertar para a atividade puramente racional? Por isso, pretender recusar a tais experiências toda a sua importância inaugural, sob o pretexto de serem elas irracionais, seria algo tão espirituoso quanto pretender recusar uma obra de arte por ela ser "alienante" e não servir para diminuir as desigualdades sociais. O vínculo entre prazer das sensações e conhecimento é apresentado, por Aristóteles, com as seguintes palavras, já de há muito conhecidas:

Todos os homens desejam, por natureza, saber. Sinal disso é o prazer das sensações; pois fora até do que há nelas de proveitoso, desejamo-las por si mesmas, e mais do que todas as outras as sensações visuais. Pois não somente para agir, mas também quando não nos propomos fazer coisa alguma, preferimos, por assim dizer, a vista a tudo o mais. Isso acontece porque ela é, entre as sensações, aquela que mais nos faz conhecer e que mais diferenças nos descobre. ${ }^{6}$

O primeiro sinal de que o homem seja um ser de conhecimento é, portanto, o fato de que para ele as sensações representam mais do que algo apenas proveitoso. As sensações nos agradam por elas mesmas, diz Aristóteles. O prazer das sensações não se reduz, no homem, à experiência de se alcançar a saciedade. Se tenho sede, seguramente sinto prazer ao saciá-la; o mesmo acontecendo com os animais. Mas o prazer das sensações significa ainda que também sentimos prazer quando nada nos falta, pelo simples contentamento de estarmos em presença de certas sensações. Este é o prazer da descoberta, um prazer puramente estético, o qual nos faz ampliar e enriquecer nossa experiência de mundo. Uma criança que descobre, pela primeira vez, o sabor do amargo sente seu mundo enriquecido e ampliado por um novo conhecimento. Tal revelação equivale à própria descoberta de que o amargo, como tal, existe, e de que o universo das sensações não se reduz ao doce e ao não-doce. Pode-se dizer, inclusive, que é a descoberta do amargo como tal o que faz com que ela insista em buscar experimentá-lo novamente.

\section{A teoria da sensação}

No De anima, Aristóteles recusa a compreensão, até então vigente, segundo a qual a sensação seria uma forma de alteração, uma espécie de movimento desencadeado diretamente no órgão sensível por algo estranho a ele. A alteração é, sem dúvida, um momento capital da sensação, mas esta última não consiste na alteração. Sentir é algo mais do que alterar-se ou sofrer uma impressão exterior; sentir é também experimentar um sentido. A sensação só se completa quando, de certo modo, ultrapassamos o impacto direto da sensação e deixamos que ela nos diga algo, pois, para Aristóteles, também a sensação é "falante": "Portanto, o experimentar uma sensação equivale ao 
simples dizer e ao perceber [noeîn]; mas quando se experimenta prazer ou dor, sentir é tal como um afirmar ou negar, um perseguir ou fugir". ${ }^{7}$

O percurso completo da sensação é assim aquele pelo qual a impressão sensível se desfaz de tudo quanto ela possua de dessemelhante e resistente para tornar-se perfeitamente assimilável à percepção sensível. O sensível deve despir-se de todo elemento de pura exterioridade que de início possuía, "pois é o dessemelhante que nos afeta, mas, tendo sido afetados, ele é de modo semelhante". ${ }^{8}$

O sensível que provoca a alteração não altera indefinidamente o órgão ou a receptividade "estética", mas só até o ponto em que se chegue à sua identificação. Somente quando cessa a alteração é que se pode dizer que aconteceu uma afecção e que se foi afetado por algo, por exemplo, uma cor. Essa cor, entretanto, já será semelhante à receptividade sensível correspondente e assimilável a esta. Toda essa operação dá-se, espontaneamente, na receptividade sensível. Desse modo, cada sentido já busca, quando sofre uma alteração, uma certa proporção, sendo também ele próprio uma proporção determinada [logos], o que the possibilita perceber, dentro de certos limites, os sensíveis correspondentes. ${ }^{9}$

Há, por conseguinte, uma impassibilidade dos sentidos correspondente à capacidade de receber e reter as formas sensíveis mediante a alteração do órgão sensível. A alteração, por si só, seria incapaz de gerar percepção sensível. Todavia, tal impassibilidade não pode prescindir da sensação naquilo que ela possui de mais exterior, o que significa dizer que ela permanece dependente da doação do particular.

A impassibilidade dos sentidos, algo que até Aristóteles não se havia ainda concebido, embora efetiva, não chega a ser autônoma, pois ela se mantém referida a algo exterior a ela própria que desencadeia a percepção. A percepção sensível depende de um impulso e de uma "excitação" advindos do exterior. Em si mesma, porém, e uma vez tendo se produzido a geração [hótan dè gennetheĩ], ela já possui o sentir que corresponde à ciência. Então o sentir em atividade é assimilável [légetai homoíos] à atividade teórica. ${ }^{10}$

Mesmo sem sofrermos agora uma alteração no órgão visual, podemos perfeitamente atualizar uma cor, por exemplo "vermelho", e dizer que se trata de uma cor intensa. Essa atualização, entretanto, continua referida a algo que, por natureza, é exterior - a cor, pois só a percebemos quando atentamos a algo particular. Não se dá, com efeito, cor em si, mas cor já é sempre a cor disto ou daquilo. A ciência, pelo contrário, refere-se aos universais, e estes se encontram, de certa maneira, na própria alma. Eis porque, segundo Aristóteles, é possível perceber teoricamente [noêsai], por si mesmo[ep' autoí], sempre que se queira, mas não é possível perceber sensivelmente [aisthánesthai] por si mesmo, pois neste caso é preciso que o sensível subsista [hypárchei]. ${ }^{11}$

O que Aristóteles está dizendo é que para percebermos sensivelmente é preciso que já tenhamos admitido um particular. A percepção sensível é devedora do particular e, por 
isso, permanece sempre referida a ele. Perceber sensivelmente significa sempre já ver as coisas como se as tivéssemos agora bem diante de nós, mesmo quando porventura elas não estejam aí diretamente presentes. Se toda percepção ou pensamento fosse sensível é assim que perceberíamos tudo, inclusive o que tomamos por menos "objetivo".

\footnotetext{
Seja o que for que esteja no centro do mundo Deu-me o mundo exterior por exemplo de realidade, E quando digo "isto é real", mesmo de um sentimento, Vejo-o sem querer em um espaço qualquer exterior,

Vejo-o com uma visão qualquer fora e alheio a mim. ${ }^{12}$
}

Esta situação persiste inclusive no caso das ciências que portam sobre as coisas sensíveis. É por essa razão que Aristóteles não admite que os jovens e inexperientes tenham aulas de ciência política, ou seja, pelo fato de a referência ao particular ser aqui obrigatória. A percepção sensível permanece vinculada a algo exterior de que ela é a percepção; ela não pode dispor livremente de seu percebido. Em última instância, o que a impede de fazê-lo é, segundo Aristóteles, o próprio caráter das coisas sensíveis. Estas, pelo fato mesmo de possuírem matéria e serem perecíveis, resistem a serem atualizadas pela percepção. Nunca é possível chegar a nada de definitivo a seu respeito, de modo que se possa repousar nelas por meio de uma definição, "pois as coisas perecíveis são obscuras para os que possuem a ciência, quando se distanciam da percepção sensível, e mesmo sendo conservadas na alma as proporções destas não haverá nem definição e nem demonstração. ${ }^{13}$ Das sensações somente as suas proporções podem ser conservadas na alma, ou seja, nos órgãos sensíveis, o que não fornece, de forma alguma, as condições suficientes para que haja conhecimento (definição e demonstração). As proporções das coisas sensíveis, na medida em que permanecem nos órgãos sensíveis, nunca chegam a se desvincular da percepção sensível que thes deu origem, sendo assim impermeáveis e irredutíveis ao conhecimento teórico.

\section{A imaginação}

A sensação possui, invariavelmente, um caráter impositivo, pelo fato mesmo de ser inseparável da alteração, mais ou menos brusca e involuntária, do órgão sensível. Algo diverso, no entanto, acontece com as imagens ou representações [phantasíai], que se constituem a partir das sensações, pois se não está à nossa disposição perceber sensivelmente, podemos perfeitamente nos colocar a imaginar tão logo queiramos. ${ }^{14}$ Além disso, o ato de imaginar, ao contrário do de opinar, não implica a nossa adesão imediata ao que foi imaginado. A imaginação, embora resulte da atividade dos sentidos, neutraliza, de alguma forma, o impacto da sensação. Em si mesmas, as imagens não são nem falsas nem verdadeiras, embora, para Aristóteles, na maior parte das vezes, elas possuam algo de ilusório. ${ }^{15}$ Enquanto tão somente imaginamos, não afirmamos, em absoluto, a existência do que é por nós imaginado. Por isso, mesmo diante dos quadros mais terríveis e dos filmes mais sangrentos podemos permanecer, até certo ponto, 
impassíveis. A imaginação, por si só, não nos faz sofrer nenhum abalo "real". O único abalo que, imaginando, podemos experimentar será aquele que nós mesmos nos concedermos voluntariamente. ${ }^{16}$ Essa distância que separa aquele que imagina da sensação em ato, se não é capaz de descolar a imagem da sensação, cria, não obstante, o espaço livre para que se constitua uma suposição [hypólepsis], seja ela opinião ou pensamento. ${ }^{17}$

Sem que a imaginação abrisse, naturalmente, um hiato que nos separa da sensação em ato, sequer haveria espaço seja para a opinião seja para o pensamento. Para pensar, para agir ou simplesmente para opinar, temos de assentir em algo que ainda não é real, caso entendamos por real a sensação em ato. Esse assentir não se configura como uma convicção, mas antes como um livre admitir.

Aristóteles, entretanto, interpreta a origem da imagem, que é também fonte de erro, como uma certa insuficiência presente na própria sensação. Não fosse, por exemplo, a distância do objeto sensível relativamente a nós, a imaginação nem sequer teria ocasião de induzir-nos ao erro, sendo a própria sensação verdadeira e suficiente: "Não é quando ativamos nossos sentidos com precisão sobre o sensível", diz ele, "que dizemos que isto nos parece ser um homem, mas antes quando não percebemos de modo suficientemente claro" ${ }^{18}$

A sensação dos sensíveis próprios, aquela que cada sentido tem do sensível que the é correspondente, é sempre verdadeira ou não comporta senão minimamente o erro. Este já se torna efetivamente possível quando se trata de julgar se o branco (sensível próprio ao sentido da visão) é isto ou aquilo. Mas é, sobretudo, relativamente aos chamados sensíveis comuns (grandeza, movimento) que costumamos no mais das vezes nos iludir, tanto mais se o objeto sensível estiver distante de nós seja no espaço seja no tempo. Em todos esses casos, porém, em que há erro no âmbito das sensações, este erro não é voluntário. Trata-se antes, propriamente falando, de ilusão do que de erro. Ela é antes fruto de distração ou de condições precárias de percepção sensível do que de algo que pudéssemos realmente evitar.

A ilusão só se torna algo grave e pleno de conseqüências quando ela é voluntária, pois é aqui que o homem erra e se torna propriamente responsável pelo erro. A imagem, por ser persistente e assemelhar-se à sensação, seduz para que pautemos por ela a nossa conduta, o que acontece à nossa inteira revelia. Mas logo que nos deixamos seduzir e agimos em conformidade com ela, como se ela fosse sensação, nisso mesmo nós erramos e nos tornamos responsáveis pelo erro, pois agir assim é aqui o próprio erro. Os animais não dispõem de inteligência [noûs] e por isso não podem errar quando se conduzem de acordo com as imagens, o que fazem regularmente. Já o homem, pelo contrário, só age determinado pelas imagens quando sua inteligência se obscurece temporariamente, seja sob o efeito do sono, da doença ou da paixão. ${ }^{19}$ Para Aristóteles, a distinção humana está em que somente o homem pode errar, ao passo que os demais 
animais, todos eles desprovidos de lógos, estão, por princípio, isentos dessa possibilidade. ${ }^{20}$

Os animais, portanto, também são freqüentados por imagens, mas neles essas imagens não podem conduzir ao erro. É que no caso dos animais as imagens não distam das sensações a ponto de serem percebidas como imagens. Somente o homem pode propriamente ver uma imagem, isto é, ser num modo de ser que lhe é correspondente. Mas o que significa aqui ver uma imagem como imagem senão perceber-admitir algo que não está aí diretamente presente? A própria fala não é em si mesma um tornar presente o que está ausente? Como ela poderia ser isso a não ser também por intermédio da imagem?

Ver uma imagem como imagem, admiti-la, só é possível se, de algum modo, nós não somos diretamente afetados por ela. A imaginação é, de certa forma, um sentido para a distância. Sem ela não há erro propriamente dito, mas tampouco pode haver acerto ou ainda algo que possa estar além do erro e do acerto. Sendo desencadeada pelos sentidos em atividade, a imaginação, ao mesmo tempo, distancia o objeto sensível e o aproxima da consideração pensante. Por diversas vezes, Aristóteles vincula, decisivamente, o pensamento à imaginação, como quando afirma que jamais a alma pode pensar sem imagens. ${ }^{21}$ Ao contrário, portanto, dos animais, para os quais as imagens assumem de pronto o lugar de sensações, no homem elas já se dispõem a serem assumidas em um certo comportamento deliberado. O homem não se depara, primeiro, de modo puramente sensível com as imagens para somente depois "neutralizálas" pelo pensamento. As próprias imagens, nele, não são tão só e unicamente sensíveis, mas já a oportunidade para determinadas ações. A fim de marcar essa diferença, Aristóteles chega a delimitar duas espécies de imagens: uma sensitiva [aisthetiké] e outra ponderativa [logistiké]. ${ }^{22}$ Somente essa última espécie de imagem concerne propriamente ao homem enquanto homem.

Aristóteles afirma que "para a alma pensante as imagens subsistem tal como as sensações". ${ }^{23}$ Com isso, não se está dizendo que se possa ver uma imagem da mesma forma que se é afetado diretamente pelo objetos sensíveis, ou seja, por intermédio dos órgãos sensíveis. O "tal como" aproxima e, ao mesmo tempo, distancia as imagens das sensações. Imagem não é sensação, mas é como se fosse... Perceber uma imagem significa recebê-la, de alguma forma, "do exterior", tal como os sentidos recebem as impressões sensíveis. "Exemplo de realidade", diria Alberto Caieiro, as imagens, mesmo sem possuírem o caráter impositivo das sensações, dispõem a alma a certas inclinações. Essa movimentação espontânea da alma permite, por sua vez, que se delibere, efetivamente, acerca de uma ação ou de um comportamento. ${ }^{24} \mathrm{O}$ decisivo aqui é notar que as imagens não são, para Aristóteles, construções subjetivas aleatórias, o que nós chamamos de "fantasias", mas antes o modo como a alma pensante acede imediatamente àquilo que é. Apenas atentando e atendo-se às imagens o pensamento pode captar o real assim mesmo como ele é e se dá a ver, vindo ao nosso encontro. 
Que as imagens não sejam apenas "imagens", mas carreguem consigo certa tendência de ver e considerar o que se apresenta, sabem-no os oradores de todos os tempos. Em sua Retórica, Aristóteles chama a atenção para o fato de que o bom orador deve ser capaz, antes de mais nada, de inclinar a sua audiência para certas disposições, caso queira tornar-se persuasivo. Assim, por exemplo, quando se deseja acalmar o auditório a respeito de alguém, deve-se fazê-lo aparecer como sendo digno de temor, de respeito ou de consideração, em virtude de algum benefício que este tenha feito; ou então como alguém que agiu contra a sua vontade e se encontra sinceramente arrependido. É que tão logo vislumbremos uma dessas imagens, naturalmente arrefece em nós a cólera a seu respeito. ${ }^{25}$

Tão logo sejam vislumbradas, as imagens despertam um movimento espontâneo na alma que já não pode ser simplesmente anulado. Esse movimento, entretanto, diferentemente do que acontece com a alteração dos órgãos sensíveis, exige uma colaboração de nossa parte. Sem a nossa participação, a imagem não pode nos inclinar a uma certa disposição; nós mesmos devemos ter permitido que ela se apresentasse. É o que se pode ver claramente na seguinte passagem:

A faculdade de perceber percebe as formas nas imagens, e como nas formas está determinado para ela o que se deve buscar ou evitar, ela se move mesmo fora da sensação, quando se volta para as imagens. Por exemplo, tendo percebido a tocha, que os sentidos dizem ser fogo, conhece, por aquilo que é comum, ao vê-la movendo-se, que há um inimigo. ${ }^{26}$

Ao perceber a tocha movendo-se, a alma pensante experimenta também um certo movimento. Esse movimento não é disparado diretamente pela alteração do órgão sensível. Não se trata propriamente de alteração.

Num acampamento militar, à noite, vê-se ao longe uma tocha em movimento. Trata-se, sem dúvida, neste caso, de uma percepção sensível, mas aqui não é esse tipo de percepção que está em causa. Trata-se antes da percepção de uma imagem como imagem. Vendo a tocha movimentar-se ao longe, o soldado sente a presença do inimigo. Pode-se até dizer que só quando o soldado sente a presença do inimigo ele viu o que ali havia para ver. Sentir o sentido, porém, não significa apenas captá-lo, significa, antes, despertar para ele. Assim, o soldado que vê, ao longe, a tocha movimentar-se, só a vê propriamente quando se reconhece como soldado à espera do inimigo. Ora, isto é o que não precisa necessariamente acontecer pela simples capacidade de captar o sinal. $\mathrm{Na}$ verdade, a tocha em movimento não é então um sinal da presença do inimigo, a tocha em movimento é aqui a própria presença do inimigo.

$\mathrm{Na}$ tocha em movimento, portanto, percebe-se a própria presença do inimigo. Mesmo não sendo ainda diretamente perceptível, o inimigo já se encontra ali presente no aprontar-se do soldado, talvez para detê-lo. Esse perceber como um preparar-se para 
algo só se concretiza a partir de uma inserção prévia que já se sintonizou com o modo de ser disso que se está percebendo. A imaginação aqui não se distingue em nada da própria percepção, pois é atendo-se à imagem que se chega a perceber a presença do inimigo. O soldado não imagina (figura para si) primeiro o inimigo para somente depois, a partir de uma reflexão, preparar-se para recebê-lo. Todavia, não fosse a disponibilidade prévia do soldado para receber o inimigo, este não teria condições de apresentar-se a partir de si mesmo na imagem. Alguém que não fosse soldado e não estivesse à espera de nenhum inimigo, poderia até entender o sinal, se este lhe fosse indicado, mas não poderia percebê-lo tal como o soldado o percebe. Para tanto, seria preciso colocar-se na situação ou na "pele" do soldado.

\section{A composição poética e a atividade do espectador}

Esse precisar colocar-se na "pele" do outro para sentir o que ele deve ter sentido é, na verdade, o espaço de jogo aberto pela imaginação, o qual constitui o terreno da vivência e da criação especificamente estéticas. Esse é o terreno do possível. Ao poeta, nos diz de maneira explícita Aristóteles, não cabe narrar o que aconteceu, mas o que poderia ter acontecido. Nem tudo, porém, que poderia ter acontecido a alguém diz respeito à composição poética, mas somente o que poderia ter acontecido "segundo a verossimilhança e a necessidade". ${ }^{27}$

O poeta não está livre para compor o que bem entenda; ele deve, ao contrário, seguir aquilo que um determinado personagem (a imagem) abre enquanto possibilidade efetiva. O poeta imita, isto é, admite e acompanha a ação una [mía práxis] ${ }^{28}$ Esta "ação una" não se deixa constatar ou detectar como algo que estivesse aí presente; ela se verifica, primeiramente, na composição poética e, em seguida, quando essa composição é lida, ouvida ou representada. Ela é algo de mais universal do que o particular visado pelo historiador, pois pertence a ela um vínculo de necessidade que permite a um personagem aparecer de uma maneira bem determinada, e não simplesmente acidental. Não é por acaso, portanto, que Aristóteles afirma ser a poesia algo mais filosófico e mais sério [philosophóteron kaì spoudaióteron] do que a história ${ }^{29}$, o que abre um importante ponto de divergência com Platão, para quem a poesia era apenas cópia das coisas particulares, elas mesmas cópias das idéias.

Partindo da imagem, isto é, da "ação una", o poeta realiza algo que é mais universal do que aquilo que consegue o historiador atendo-se apenas às particularidades factuais. Por isso, também o leitor de poesia ou o espectador de teatro faz algo mais do que ocupar o seu tempo com a vida alheia. Vivendo concretamente as vicissitudes de um personagem, colocando-se em sua pele, o leitor ou o espectador (Aristóteles tem em vista especialmente este último) alcança algo efetivamente universal. Ele se confia a uma presença digna de ser recebida e....admirada. 
O leitor ou o espectador sai realmente de si para deixar que um outro seja, isto é, se apresente. Mas esse outro não é simplesmente alheio, e sim alguém que se faz, por si mesmo e desde si mesmo, presente, que nos concerne com a sua presença. Precisamente essa atenção àquilo que assim se apresenta é o que constitui a vida da atividade teórica e de todo conhecimento, como vimos no início deste trabalho. A atividade teórica e a atividade do espectador são, portanto, a mesma atividade, ou como diz Aristóteles: "o filósofo é também ele um filômito".

\section{BIBLIOGRAFIA COMPLEMENTAR}

AUBENQUE, P. Le problème de l'être chez Aristote: Essai sur la problématique aristotélicienne. Paris: PUF-Quadriage, 2002.

BERTI, E. As razões de Aristóteles. Tradução de Dion D. Macedo. São Paulo: Loyola, 1998.

CRUBELLIER, M.; PELLEGRIN, P. Aristote: Le philosophe et les savoirs. Paris: Éditions du Seuil, 2002.

JAEGER, W. Aristóteles. Tradução de José Gaos. Cidade do México: Fondo de Cultura Económica, 2001.

SANTORO, F. Poesia e verdade: Interpretação do problema do realismo a partir de Aristóteles. Rio de Janeiro: Sette Letras, 1994.

STIRN, François. Compreender Aristóteles. Tradução de Ephraim F. Alvez. Petrópolis: Vozes, 2006.

\section{* Francisco José Dias de Moraes é doutor em filosofia pela UFRJ/PPGF.}

${ }^{1}$ É famosa a definição de filosofia apresentada por Aristóteles no início de sua Metafísica, segundo a qual a filosofia é a ciência de todas as coisas sem ser a ciência de nenhuma delas em particular.

${ }^{2}$ ARISTÓTELES. The Nichomachean Ethics. Edição bilingüe. Tradução de H. Rackhan. London: Harvard University Press, 1992, I, 3, 1094 b 13.

${ }^{3} \mathrm{O}$ filósofo em questão é Thomas S. Kuhn, cujas teses principais foram desenvolvidas no livro $A$ estrutura das revoluções científicas.

${ }^{4}$ ARISTÓTELES. Metafísica. Edição trilingüe. Tradução de V.G.Yebra. Madrid: Gredos, 1998, I, 2, 982b 12-21: [dià gàr tò thaumázein oi ánthropoi kai nûn kai tò prôton érxanto philosopheîn, ex arkhês mèn tà prókheira tôn atópon thaumásantes, eîta katà mikròn ohúto proïóntes kaì perì tôn meizónon diaporésantes, ohîon perí te tôn tês selénes pathemáton kai tôn perì tòn hélion kai ástra kaì perì tês toû pantòs genéseos. Ho $d^{\prime}$ aporôn kaì thaumázein oíetai agnoeîn (diò kaì ho philómuthos philósophos pós estin: ho gàr mûthos súnkeitai ek thaumasion); óst' eíper dià tò pheúgein tèn ágnoian ephilosóphesan, phaneròn hóti dià tò eidénai tò epistasthai edíokon kaì ou khréseós tinos héneken.]

${ }^{5}$ Sabe-se que a palavra belo remonta ao latim bellum e, assim, ao verbo grego bállo, o qual significa arremessar, lançar. Seguindo a pista deixada pela origem da palavra, belo seria, assim, o que está lançado, mas de tal modo que não se pode supor nada nem ninguém que o tenha lançado; aquilo que, no momento em que o descobrimos, já não remete a nada fora de si mesmo, mas apenas a si mesmo.

${ }^{6}$ Ibidem, I, 1, 980a: [Pántes ánthropoi toû eidénai orégontai phúsei. Semeîon d' he tôn aisthéseon agápesis; kaì gàr khorìs tês kheías agapôntai di' ahutás, kaì málista tôn állon he dià tôn ommáton. Ou gàr mónon hína práttomen allà kaì medèn méllontes práttein tò horân ahiroúmetha antì pánton 
hos eipêin tôn állon. Aítion d' hóti málista poieî gnorizein hemâs aúte tôn aisthéseon kaì pollàs deloî diaphorás.]

${ }^{7}$ ARISTÓTELES. On the Soul. Edição bilingüe. Tradução de W.S.Hett. London: Harvard University Press, 2000, III, 7, 431a 8.

${ }^{8}$ Ibidem, II, 5, 417a 20.

${ }^{9}$ Sobre essa compreensão de lógos como proporção são importantes as seguintes palavras de Barbara Cassin: "Permanece o fato de que, de qualquer modo, e como Aristóteles não cessa de repetir, a aisthêsis é, sem dúvida alguma, um 'poder crítico'. Proponho compreender aqui, em um primeiro nível ligado ao estatuto de lógos-relação, que a sensação primeiramente 'julga', no sentido de que avalia a proporção respectiva dos contrários que caracteriza tal sentido [senti]. Ela afeta o cálculo da relação, faz o que chamaríamos de 'média' dos contrários, e é a partir dessa ponderação (algo como 'três vezes mais de preto do que de branco') que ela sente: cinza”. Cf. CASSIN, B. Aristóteles e o Lógos: contos de fenomenologia comum. São Paulo: Loyola, 1999, p. 170.

${ }^{10}$ ARISTÓTELES. On the Soul. Op. cit., II, 5, 417b 16.

${ }^{11}$ Ibidem, II, 5, 417b 24.

${ }^{12}$ CAIEIRO, Alberto. Poesia. São Paulo: Companhia das Letras, 2001, p. 135.

${ }^{13}$ ARISTÓTELES. Metafísica. Op. cit., VII, 15, 1040a 2.

${ }^{14}$ ARISTÓTELES. On the Soul. Op. cit., III, 3, 427b 18.

${ }^{15}$ Ibidem, III, 3, 428a 12.

${ }^{16}$ Um dos elementos centrais das tragédias é, segundo nos diz Aristóteles no cap. VI de sua Poética (1449b 23), a purgação [kátharsis] de certas emoções, mais precisamente, da piedade e do temor. Essa purgação, que Aristóteles faz entrar na própria definição da tragédia, acontece quando nos permitimos sentir medo e piedade dentro do espaço delimitado da apresentação cênica. Não fosse essa distância, própria da imaginação, e o temor e a piedade, antes de serem purificados, seriam, na verdade, exacerbados, e em lugar de purificação teríamos insensibilidade ou desespero.

${ }^{17}$ ARISTÓTELES. On the Soul, III, 3, 427b 16.

${ }^{18}$ Ibidem, III, 3, 428a 13.

${ }^{19}$ Ibidem, III, 3, 429a 5.

${ }^{20}$ Ibidem, III, 3, 427b 13.

${ }^{21}$ Ibidem, III, 7, 431a 17.

22 Ibidem, III, 9, 433b 30.

${ }^{23}$ Ibidem, III, 7, 431a 14.

${ }^{24}$ ARISTÓTELES. Retórica das paixões. Edição bilingüe. Tradução de Ísis Borges B. Da Fonseca. São Paulo: Martins Fontes, 2003, II, 5, 1383a 6: "Pois o medo nos torna deliberantes, ao passo que ninguém delibera acerca daquelas coisas que já não prometem mais nada".

${ }^{25}$ Ibidem, II, 3, 1380 b 30.

${ }^{26}$ ARISTÓTELES. On the Soul Op. cit., III, 7, 431b 2: [Tà mèn oûn eíde tò noetikòn em toîs phantásmasi noeî, kai hos en ekeínois hóristai autoî tò dioktòn kaì pheuktón, kaì ektòs tês aisthéseos, hótan epi tôn phantasmáton eî, kineîtai, oîon aisthanómenos tòn phruktòn hóti pûr, teî koineî gnorízei, horôn kinoúmenon, hóti polémios]

${ }^{27}$ ARISTÓTELES. Poética. Edição bilingüe. Tradução de Eudoro de Souza. São Paulo: Ars Poética, 1993, IX, 1451b 1. 
${ }^{28}$ Ibidem, VIII, 1451a 21.

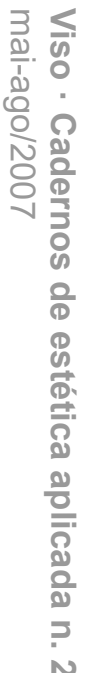

${ }^{29}$ Ibidem, IX, 1451b 6. 